Bangladesh Journal of Neuroscience 2014; Vol. 30 (1) : 11-15

\title{
Identification of Central Nervous System Complications Related To Eclampsia
}

\author{
MURSHED BAQUI ${ }^{1}$, MOHAMMAD SHAH JAHIRUL HOQUE CHOWDHURY ${ }^{2}$, MD. TAUHIDUL ISLAM
}

CHOWDHURY $^{3}$, PARITOSH KUMAR SARKAR ${ }^{4}$, MD. NAHIDUL ISLAM ${ }^{5}$, QUAZI DEEN MOHAMMAD ${ }^{6}$

\begin{abstract}
:
Background: Eclampsia is a complex hypertensive disorder of pregnancy affecting multiple systems. Central nervous system is commonly affected and is a cause of significant morbidity and mortality in women. Various neurological complications are found in eclamptic patients. Aims and Objectives: The aim of this study was to explore the various CNS complications related to eclampsia. Materials and Methods: This retrospective observational study was carried out in the 'Eclampsia ward' of Department of Gynaecology and Obstetrics of Dhaka Medical College Hospital (DMCH), during the period of November, 2010 to October, 2011 in patients admitted with a history of eclampsia. Fifty(50) patients were included in this study. Data was collected by a semistructured questionnaire. The patients were interviewed and a complete clinical examination was performed by the investigator. It was reviewed by a consultant neurologist. Results \& conclusion: The results revealed that patients had headache, comatose state, stroke, focal neurological deficit, post partum psychosis, aphasia and cortical blindness. Death occurred in $6.0 \%$ of patients. As eclampsia is the third major cause of pregnancy related maternal death in Bangladesh (16\%), and no study has yet not been reported in this field, this study might help in formulating management plan; predict prognosis and functional recovery in the individual cases.
\end{abstract}

Introduction:

Eclampsia is one of the dreaded complications of pregnancy as it carries high morbidity and mortality to the mother and baby. The incidence of eclampsia depends on a variety of factors and varies widely from region to region.

Both the International Society for the Study of Hypertension in Pregnancy (ISSHP) and the Working group on High Blood Pressure in Pregnancy (WGHBPP 1990) have recommended the following definitions. Accordingly pre-eclampsia is defined as occurrence of hypertension along with proteinuria or edema or both after 20 weeks of gestation and when convulsions or unexplained coma occur in the setting of gestational hypertension, the condition is referred to as eclampsia. In this context, hypertension is defined as blood pressure above $140 / 90 \mathrm{mmHg}$ (measured on two occasions, $4 \mathrm{~h}$ apart) and proteinuria as urinary protein excretion over $300 \mathrm{mg}$ per $24 \mathrm{~h}$ ( $30 \mathrm{mg} / \mathrm{dl}$ on random sample or e" $1+$ on dipstick). It is more common in developing countries because illiteracy, lack of health awareness and education, poverty, and superstitious believes prevent women from seeking medical advice during pregnancy ${ }^{1,2}$.

The incidence of eclampsia is high in Bangladesh$7.9 \%$ (not including pre-eclampsia), according to the results of a house-to-house survey ${ }^{3}$.

A neurological complication is defined as any manifestation secondary to neuronal dysfunction in patients with eclampsia. Common symptoms include

1. Medical Officer, National Institute of Neurosciences and Hospital, Sher-E- Bangla Nagar, Dhaka.

2. Assistant Professor cum Resident Physician, National Institute of Neurosciences and Hospital, Sher-E- Bangla Nagar, Dhaka.

3. Assistant Professor, National Institute of Neurosciences and Hospital, Sher-E- Bangla Nagar, Dhaka.

4. National Institute of Neurosciences and Hospital, Sher-E- Bangla Nagar, Dhaka.

5. Registrar, National Institute of Neurosciences and Hospital, Sher-E- Bangla Nagar, Dhaka.

6. Professor, National Institute of Neurosciences and Hospital, Sher-E- Bangla Nagar, Dhaka 
headache, blurring of vision, aphasia, facial nerve palsy, cerebrovascular accident, transient ischaemic attack, cerebral edema, comatose state, postpartum psychosis, cortical blindness, transient blindness, retinal edema etc ${ }^{4}$.

The World Health Organization (WHO) estimates that only $40 \%$ of births in developing countries take place in health facilities ${ }^{5}$. When delivery care is sought, it is done late, after a lot of delays and this contributes to maternal mortality. The aim of this study to identify the central nervous system complications and its pattern related to eclampsia.

Methods and Materials: This retrospective hospital based observational study was carried out in the Eclampsia ward of Department of Gynaecology and Obstetrics, Dhaka Medical College Hospital. The study period was $1^{\text {st }}$ November 2010 to $31^{\text {st }}$ October 2011. Fifty(50) eclamptic patients were sampled by purposive (non-random) sampling. Patients with features of eclampsia confirmed by consultant gynaecologist and having central nervous system complications diagnosed clinically and evaluated by neurologist were included. Patients having any pre-existing neurological deficit were excluded. Data was collected by a semi-structured questionnaire. The patients of eclampsia were identified by a consultant gynaecologist on the basis of diagnostic criteria $^{1,2}$. All patients of eclampsia during the study period were interviewed and examined. Patients with central nervous system complications were isolated. A complete clinical examination was performed by the investigator after 24 hours of proper management of eclampsia and was repeated 24 hourly for three occasions for newer central nervous system features. It was reviewed by a consultant neurologist before reaching final diagnosis. Information was obtained from the patient as well as from the witness usually a family member or hospital staff. Clinical features and examination findings were noted. Those patients found having central nervous system complications in clinical examination were sent for CT scan of head in Department of Radiology and Imaging, Dhaka Medical College Hospital. CT scans of head were performed by standard CT scan machine (Somatom emotion Duo, Duel slice, Siemens). The images were reported by the same radiologist in all cases. Relevant data and findings were recorded in a preformed data sheet for each patient. The different variables of the data were analyzed with the help of SPSS (Statistical Program for Social Science) software version 16. Statistical analysis was done by appropriate procedure. The results were presented as tables and analyzed accordingly. Prior to the commencement of this study, the research protocol was approved by the thesis committee (Local Ethical Committee).

\section{Results:}

In this retrospective hospital based observational study a total number of 50 eclamptic patients having central nervous system complications were enrolled and the results of the study were presented here.

Table-I

Age distribution of the eclamptic patients associated with CNS complications $(n=50)$

\begin{tabular}{lcc}
\hline $\begin{array}{l}\text { Age of the patient } \\
\text { (Years) }\end{array}$ & $\begin{array}{c}\text { Number of } \\
\text { patients }\end{array}$ & Percentage \\
\hline $15-20$ & 23 & 46.0 \\
$21-25$ & 14 & 28.0 \\
$26-30$ & 5 & 10.0 \\
$31-35$ & 6 & 12.0 \\
$36-39$ & 2 & 4.0 \\
\hline Total & 50 & 100.0 \\
\hline
\end{tabular}

Range : 15-39 years; Mean \pm SD : $22.9 \pm 6.1$

Table-I showed that the mean age of patients having features of eclampsia was found $22.9 \pm 6.1$ years ranging from 15-39 years and maximum number $(46.0 \%)$ was found in the age group of $15-20$ years. $28.0 \%$ of patients were found in the age group of $21-25$ years and only $4.0 \%$ of patient were above 35 years of age.

Table-II

Other socio-demographic characteristics of the subjects $(n=50)$

\begin{tabular}{llcc}
\hline Variables & & \multicolumn{2}{c}{ Patients } \\
\cline { 3 - 4 } & & Number & Percentage \\
\hline Habitat & Urban & 18 & 36.0 \\
& Rural & 32 & 64.0 \\
Education & Illiterate & 12 & 24.0 \\
& Primary & 29 & 58.0 \\
& Secondary & 6 & 12.0 \\
& SSC & 3 & 6.0 \\
Family & $<10000$ & 39 & 78.0 \\
Monthly & $10001-20000$ & 9 & 18.0 \\
income (Tk.) & $20001-30000$ & 2 & 4.0 \\
\hline
\end{tabular}


Table-Il showed sample descriptions of sociodemographic variables that $36.0 \%$ of patients were residing in urban area and $64.0 \%$ in rural area. $58.0 \%$ of patients were educated up to primary level, and $24.0 \%$ were illiterate. $78.0 \%$ of patients had a monthly family income of less than 10,000 Tk.

Table-III

Distribution of antenatal care in eclamptic patients with CNS complications $(n=50)$

\begin{tabular}{lcc}
\hline Antenatal care & Number of patients & Percentage \\
\hline Never & 39 & 78.0 \\
$1-3$ times & 11 & 22.0 \\
\hline Total & 50 & 100.0 \\
\hline
\end{tabular}

Table-III showed that $78.0 \%$ of the patients never went to any antenatal care center for present pregnancy and only $22.0 \%$ of the patients received antenatal care for 1 to 3 times.

Table-IV

Distribution of time of development of eclampsia with central nervous system complications $(n=50)$

\begin{tabular}{lcc}
\hline Time & Number of Patient & Percentage \\
\hline Prepartum & 38 & 76.0 \\
Postpartum & 12 & 24.0 \\
\hline Total & 50 & 100.0 \\
\hline
\end{tabular}

Table-IV showed $76.0 \%$ of patients had prepartum eclampsia whereas $24.0 \%$ had post partum eclampsia that developed central nervous system complications.

\section{Table-V}

Distribution of gestational age of pregnancy of prepartum eclamptic patient at admission $(n=38)$

\begin{tabular}{lcc}
\hline $\begin{array}{l}\text { Gestational age } \\
\text { (Weeks) }\end{array}$ & $\begin{array}{c}\text { Number of } \\
\text { Patients }\end{array}$ & Percentage \\
\hline $26-28$ & 2 & 5.26 \\
$29-32$ & 5 & 13.16 \\
$33-36$ & 16 & 42.11 \\
$37-40$ & 15 & 39.47 \\
\hline Total & 38 & 100.00 \\
\hline
\end{tabular}

Range : 26-40 weeks; Mean \pm SD : 35.1 \pm 3.4 weeks
Table-V showed that $42.11 \%$ of patients developed eclampsia during the gestational age of 33-36 weeks and $39.47 \%$ of patients at their late pregnancy. Only $18.42 \%$ of patients had eclampsia before gestational age of 32 weeks. Mean gestational age was 35.1 weeks with a standard deviation of 3.4 weeks.

Table-VI

Distribution of parity of eclamptic patients with CNS complications $(n=50)$

\begin{tabular}{lcc}
\hline Parity & $\begin{array}{c}\text { Number of } \\
\text { Patients }\end{array}$ & Percentage \\
\hline Primigravida & 29 & 58.0 \\
$2-3$ & 13 & 26.0 \\
$>4$ & 8 & 16.0 \\
\hline Total & 50 & 100 \\
\hline
\end{tabular}

Table-VI showed $58.0 \%$ of patients who developed eclampsia with central nervous system complications were primigravida while $26.0 \%$ of patients had 2-3 parity and only $16.0 \%$ of patients had e"4 parity.

Table-VII

Pattern of CNS complications in eclamptic patients $(n=50)$

\begin{tabular}{lcc}
\hline Complications & $\begin{array}{c}\text { Number of } \\
\text { Patients* }\end{array}$ & Percentage \\
\hline Aphasia & 6 & 12.0 \\
Headache & 23 & 46.0 \\
Focal neurological deficits & 9 & 18.0 \\
Stroke & 11 & 22.0 \\
Cortical blindness & 4 & 8.0 \\
Post partum psychosis & 8 & 16.0 \\
Comatose state & 17 & 34.0 \\
Death & 3 & 6.0 \\
\hline
\end{tabular}

${ }^{*}$ Multiple responses

Table-VII. showed that $46.0 \%$ of patients had headache, then $34.0 \%$ had comatose state, $22.0 \%$ stroke, $18.0 \%$ focal neurological deficits, $16.0 \%$ post partum psychosis, $8.0 \%$ cortical blindness. Death occurred in $6.0 \%$ of cases.

Discussion:

The present study was carried out with an aim to find out central nervous system complications related to eclampsia in the perspective of 
Bangladesh. The socio-demographic profile (age, body weight, socio-economic status and parity) of the patients, antenatal care, gestational age, and its relation to develop central nervous system complications in eclampsia and maternal outcome were evaluated.

A Clinical Study of 100 Cases of Eclampsia In Rajshahi Medical College Hospital (RMCH) found the socioeconomic status, level of education, the quality of patients' nutrition and antenatal care of the patients were very low ${ }^{6}$. Another study found that eclampsia was more common below 20 years $(6.97 \%)$ of age group, primi-mother $(7.43 \%)$, lower socio-economic status $(5.67 \%)$ and in unbooked $(6.41 \%)$ cases $^{7}$. The current study also featured almost same findings in the patients of eclampsia who developed central nervous system complications such as age below 20 years, primigravida, late gestational age, lower socioeconomic status, illiterate or primary level of education, no or a few antenatal care. These results were comparable with other results.

In a study at Eclampsia ward in Dhaka Medical College Hospital in the year of 1998 to 2000 with 2956 eclamptic patients found the incidence of eclampsia with different complications was $21.0 \%$, which included central nervous system complications with coma $(2.9 \%)^{8}$. Eclampsia study in $\mathrm{RMCH}$ found only $4.0 \%$ of patient as eclampsia with central nervous system complications ${ }^{6}$. Another study in Mayo Hospital Lahore found 7.0\% central nervous system complications in a study ${ }^{9}$. Sibai and Ustav (1995) found that about $6.5 \%$ of the patients with eclampsia develop neurological complications ${ }^{10}$. In this current study the incidence of central nervous system complications found were $4.77 \%$. These findings were consisted with the current study. While Okanloma and Moodley (2000) in a study in Darban, South Africa found neurological complication rate only $0.9 \%$ which truly reflects its better health services of their community ${ }^{7}$.

In the same study it was revealed that out of 140 eclamptic women with neurological complications it was found that $37.5 \%$ of patients had hemiparesis, $12.5 \%$ hemiplegia, $6.25 \%$ monoparesis, $18.75 \%$ facial nerve palsy, $12.5 \%$ transient blindness $(<6$ hours), $6.25 \%$ cortical blindness (>48 hours),
$18.75 \%$ post partum psychosis, $6.25 \%$ transient ischaemic attack and $6.25 \%$ comatose state ${ }^{7}$. Sibai and Ustav (1995) found followings as common neurological complications in eclampsia that include cortical blindness, aphasia, limb weakness, psychosis, coma or cerebrovascular accident ${ }^{10}$. Douglas et al. (1994) ${ }^{11}$,Katz et al. (2000) ${ }^{12}$ and Chames et al. (2002) ${ }^{13}$ in separate studies found that persistent occipital or frontal headaches, blurred vision, photophobia, and altered mental status. Patients might experience at least one of these symptoms in $59-75 \%$ of the cases. Headaches were reported by $50-75 \%$ of the patients, whereas visual changes were reported in $19-32 \%$ of the patients ${ }^{11-13}$.In the current study shown that $46.0 \%$ of patients had headache, then $34.0 \%$ had comatose state, $22.0 \%$ stroke, $18.0 \%$ focal neurological deficits, $16.0 \%$ post partum psychosis, $8.0 \%$ cortical blindness. Death occurred in $6.0 \%$ of cases. These findings support the present study.

There were different range of maternal mortality in different region and different areas of same region. Eclampsia is an important cause of maternal death in many parts of Africa, Asia, the Caribbean, and Latin America. Nigeria has one of the highest rates of maternal mortality in the world. There are several studies in Nigeria. All of those study showed that eclampsia has been noted to be among the most common causes of maternal mortality in Nigeria. Tukur et al. (2007) ${ }^{14}$ in Birnin Kudu found eclampsia contributed $43.1 \%$, while lgbafe et al. (2004) ${ }^{15}$ in Yenagoa $40.0 \%$ and Aboyeji et al. (2004) ${ }^{16}$ in llorin $27.5 \%$ of all maternal deaths. Rathore et al. (2010) found maternal mortality due to eclampsia was around $24.0 \%$ in a hospital based study in Lahore, Pakistan ${ }^{9}$. In Rajshahi Medical College Hospital, Khanum et al. (2004) found maternal mortality due to eclampsia was $16.0 \%{ }^{6} .{ }^{6} \mathrm{Pal}(2011)$ found that the overall maternal mortality rate was $6.05 \%$ in Burdwan Medical College Hospital, Kolkata ${ }^{7}$.In this current study maternal mortality due to central nervous study complications was $6.0 \%$.

\section{Conclusion:}

Central nervous system complications remained as important cause of morbidity and mortality of eclampsia of pregnancy. Younger age groups, low 
socioeconomic status, lack of education, primigravida, avoidance of antenatal care were commonly observed in patients who developed eclampsia with central nervous system complications.

\section{Referrances:}

1. Davey DA, MacGillivray I. The classification and definition of the hypertensive disorders of pregnancy. Am. J. Obstet. Gynecol. 1988; 158:892-898.

2. WGHBPP (Working Group on High Blood Pressure in Pregnancy), 1990. Consensus report. Am. J. Obstet. Gynecol. 1990; 163: 1689-712.

3. BIRPERT. Bangladesh Institute of Research for Promotion of Essential and Reproductive Health and Technologies. Proceeding of Dissemination Workshop on Maternal Morbidity Study. Hotel Sheraton, Dhaka 1994.

4. Okanloma KA, Moodley J. Neurological complications associated with the preeclampsia/ eclampsia syndrome. International Journal of Gynecology \& Obstetrics 2000; 71 : 223-25.

5. WHO. Coverage of maternity care. A list of available information. Geneva, Switzerland: Maternal and newborn health/Safe Motherhood. 1997.

6. Khanum M, Ashraf F, Sahrin H: A Clinical Study of 100 Cases of Eclampsia In Rajshahi Medical College Hospital. TAJ Dec 2004; 17( 2):80-3.

7. Pal A, Bhattacharyya R, Adhikari S, Roy A, Chakrabarty D, Ghosh P, Banerjee C. in Eclampsia-scenario in a hospital- a ten years study. Bangladesh Med Res Counc Bull 2011; 37: $66-70$
8. Begum MR, Begum A, Quadir E. et al: Eclampsia: Still a Problem in Bangladesh. Med Gen Med 2004; 6(4): 52.

9. Rathore R, Butt NF, Iqbal A, Khan MZU. Complications and outcome of patients of preeclampsia and eclampsia presenting to medical wards of Mayo Hospital Lahore. Ann King Edward Med Uni 2010;16(1):17-9.

10. Sibai BM, Ustav IM. Emergent management of puerperal eclampsia. Obstet. Gynecol. Clin. North Am. 1995; 22: 315-335.

11. Douglas KA, Redman CW. Eclampsia in the United Kingdom. BMJ. Nov 26 1994;309(6966):1395-400.

12. Katz VL, Farmer R, Kuller J. Preeclampsia into eclampsia: toward a new paradigm. Am J Obstet Gynecol 2000;182: 1389-96.

13. Chames MC, Livingston JC, Invester TS, Barton JR, Sibai BM. Late postpartum eclampsia: a preventable disease? Am J Obstet Gynecol 2002;186:1174-7.

14. Tukur J, Umar BA, Rabi'u A. Pattern of eclampsia in a tertiary health facility situated at a semi rural town in Northern Nigeria. Ann Afr Med 2007;6:164-7.

15. Igbafe AA, Bariweni AC, Bennibor J, Gharoro EP. The Contribution of eclampsia to maternal mortality at the Federal Medical Center, Yenagoa. Trop J Obstet Gynaecol 2004;21:S910.

16. Aboyeji AP, ljaiya MA, Fawole AA. Maternal mortality in a Nigerian teaching hospital: A continuing tragedy. Trop J Obstet Gynaecol 2004;21:S8. 